\title{
Editorial
}

\section{Yet Another Vitamin D Analogue for the Management of Secondary Hyperparathyroidism: A Triton among the Minnows?}

\author{
Yoshitsugu Obi Kamyar Kalantar-Zadeh \\ Division of Nephrology and Hypertension, Harold Simmons Center for Kidney Disease Research and Epidemiology, \\ University of California Irvine, Orange, Calif., USA
}

In patients with advanced chronic kidney disease (CKD) and particularly in those undergoing maintenance dialysis, an elevated blood level of parathyroid hormone (PTH) is common, which is referred to as secondary hyperparathyroidism (SHPT). The expression and release of fibroblast growth factor-23 (FGF23) from osteocytes is increased as a consequence of phosphorus retention in the setting of decreased glomerular filtration rate [1]. Elevated FGF23 inhibits 1 $\alpha$-hydroxylase expression in renal proximal tubular cells. Together with tubular damage, a marked reduction in 1 1a,25-dihydroxyvitamin $\mathrm{D}$ $\left(1 \alpha, 25(\mathrm{OH})_{2} \mathrm{D}\right)$, the active form of vitamin $\mathrm{D}$, ensues. Given the decline in gastrointestinal (GI) absorption of calcium as a result of inadequate activation of vitamin D receptors (VDR) in the GI tract, progressive hypocalcemia ensues. Suboptimal activation of the VDR in the parathyroid glands lead to higher expression and release of PTH, which is aggravated through signal pathways via calcium-sensing receptors (CaSR) in the parathyroid gland cells and also involves Klotho receptors. These processes can lead to compensatory proliferation of the parathyroid gland cells, leading to less responsive SHPT $[2,3]$. A clinically important consequence of untreated SHPT is loss of minerals from the bone, which leads to what is known as renal osteodystrophy.

\section{KARGER}

E-Mail karger@karger.com

www.karger.com/ajn
Given the distorted 1 $a$-hydroxylase system in CKD patients, administration of precursors of vitamin $\mathrm{D}$ such as cholecalciferol (D3) or ergocalciferol (D2), also known as nutritional vitamin $\mathrm{D}$ agents, is often ineffective. Hence, active vitamin $\mathrm{D}$ analogues including synthetic calcitriol and alfacalcidol (which increase the circulating levels of $\left.1 \alpha, 25(\mathrm{OH})_{2} \mathrm{D}\right)$ or vitamin $\mathrm{D}$ mimetics including paricalcitol and maxacalcitol (which decrease the circulating level of intrinsic $\left.1 \alpha, 25(\mathrm{OH})_{2} \mathrm{D}\right)$ have been used to correct SHPT [4]. However, if not managed well, parathyroid glands develop progressive monoclonal and nodular hyperplasia and are rendered less responsive to medical treatment due to reduced expression of VDR and CaSR. In this case, administration of even higher doses of active vitamin $\mathrm{D}$ analogs or D-mimetics may be necessary to lower PTH levels. Such aggressive treatment often causes or worsens hypercalcemia and hyperphosphatemia by enhancing intestinal absorption of calcium and phosphorus. Use of calcimimetics may be more effective under such circumstances, but profound hypocalcemia and - in CKD patients with residual kidney function - worsening

Comments on 'Use of 2MD, a Novel Oral Calcitriol Analog, in Hemodialysis Patients with Secondary Hyperparathyroidism'. (c) 2016 S. Karger AG, Basel

0250-8095/16/0433-0221\$39.50/0
Kamyar Kalantar-Zadeh, MD, MPH, PhD

Harold Simmons Center for Kidney Disease Research and Epidemiology University of California Irvine, 101 The City Drive South, City Tower Suite 400 - ZOT 4088, Orange, CA 92868 (USA)

E-Mail kkz@uci.edu 


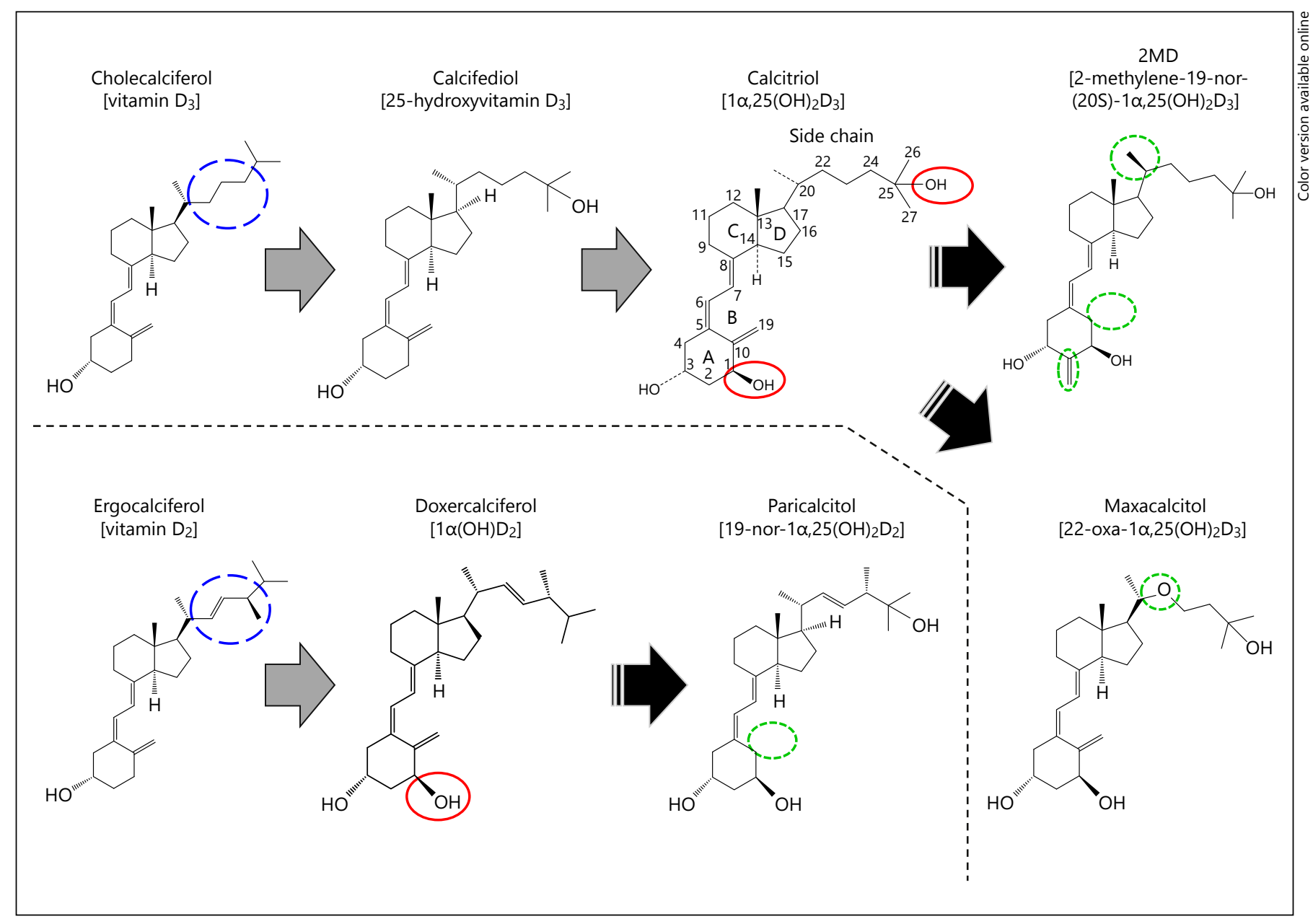

Fig. 1. Chemical structure of vitamin D compounds including doxercalciferol, paricalcitol, maxacalcitol and $2 \mathrm{MD}$.

hyperphosphatemia may ensue, reflecting medical parathyroidectomy and hungry bone syndrome [5].

There have been many attempts to develop less calcemic and less phosphatemic versions of active vitamin D analogs or mimetics with acceptable efficacy by modifying the structure of vitamin $\mathrm{D}$ [3]. These agents have different biological properties based on chemical modifications in the A-ring, seco-B ring, central CD-ring or side chains (fig. 1). With a 'trial and error' approach, several modifications including 19-nor and 22-oxa were found to have such favorable characteristics for the management of SHPT while the latter analogues indeed lower the circulating level of intrinsic calcitriol; hence, they are referred to as D-mimetics to distinguish them from true vitamin D analogues that are converted to calcitriol $[4,6]$. Although the mechanisms and different properties of these agents are not fully understood, differences in phar- macokinetics due to lower affinity to vitamin D-binding protein (DBP) may explain - at least in part - the less calcemic effect and different potency of these medications; their free (unbound) levels quickly reach peak levels in the target tissues followed by speedy disappearance, the rate of which is based on differences in CYP21A1-associated metabolism of vitamin $\mathrm{D}$ and the affinity to VDR.

In this issue of American Journal of Nephrology, Pandy et al. [7] reported the first clinical study of 2-methylene19 -nor-(20S)-1 $\alpha, 25(\mathrm{OH})_{2} \mathrm{D}_{3}$, also known as $2 \mathrm{MD}$, in dialysis patients. Although $2 \mathrm{MD}$ molecule exhibits certain similarities in its structure to paricalcitol, that is, 19-nor$1 \alpha, 25(\mathrm{OH})_{2} \mathrm{D}_{2}$, it binds to VDR with a similar affinity as calcitriol and paricalcitol but its interaction with DBP is exceedingly weaker than paricalcitol. A previous animal study of uremic rat model has demonstrated that intraperitoneal administration of $2 \mathrm{MD}$, compared to parical- 
citol, more effectively attenuated the development of SHPT at equivalent calcemic doses. In the current study by Pandy et al. [7], 24 hemodialysis patients completed the 4 -week, thrice-weekly oral $2 \mathrm{MD}$ treatment at doses ranging from 110 to $550 \mathrm{ng}$ ( $\mathrm{n}=5-8$ in each group). There was a dose-dependent efficacy of 2MD on PTH suppression; serum intact PTH concentrations decreased by $\geq 30 \%$ among half of patients in the 440 and $550 \mathrm{ng}$ group at week 4 . No patients experienced hypercalcemia defined by a serum calcium level $>10.6 \mathrm{mg} / \mathrm{dl}$.

There are several distinctions to be acknowledged in addition to the limited statistical power due to the small sample size. First, patients had relatively low serum calcium concentrations at baseline (overall mean $<9.0 \mathrm{mg} /$ dl) compared to the definition of hypercalcemia $(>10.6$ $\mathrm{mg} / \mathrm{dl}$ ). Additionally, this study did not have a control group, and serum calcium concentrations decreased by $0.5 \pm 0.7 \mathrm{mg} / \mathrm{dl}$ in the $110 \mathrm{ng}$ per treatment group and increased by $0.4 \pm 0.4 \mathrm{mg} / \mathrm{dl}$ even in the $330 \mathrm{ng}$ per treatment group during the study period, suggesting an almost $1.0 \mathrm{mg} / \mathrm{dl}$ net difference between the 2 groups after 4 weeks of treatment. The dose-dependent increase in serum calcium concentrations by $2 \mathrm{MD}$ was also shown in a previous randomized controlled trial in postmenopausal women [8]. Therefore, it remains to be determined whether $2 \mathrm{MD}$ has less calcemic property with retained suppressive effects on PTH in hemodialysis patients when compared to other active vitamin $\mathrm{D}$ analogs.

These data remind us of the developmental history of paricalcitol. The debut of paricalcitol stood out then as it was suggested to be less calcemic and less phosphatemic than calcitriol in both uremic rats and hemodialysis patients $[9,10]$. Paricalcitol was the dominant medication for management of SHPT in US hemodialysis patients in mid-to-late 2000s, but its use declined substantially in late 2010 and early 2014, in that it decreased from $>80$ to $\sim 40 \%$ and then to $\sim 10 \%$, respectively, with a concomitant increase in the use of doxercalciferol, that is, $1 \alpha(\mathrm{OH})$ $\mathrm{D}_{2}$ [11]. Doxercalciferol is as effective as calcitriol [11], but there are no large head-to-head clinical trials that compared paricalcitol with doxercalciferol, although paricalcitol has been compared to other vitamin $D$ agents $[12,13]$. Nevertheless, no meaningful changes have been observed in serum concentrations of calcium and phosphorus overtime in US dialysis patients despite these substantial changes in practice pattern, suggesting that the difference in the calcemic and phosphatemic effects among available active vitamin $\mathrm{D}$ analogs may be much smaller in the real world scenario than in the randomized clinical trials of paricalcitol reported in 2003 [10]. Indeed, in the latter study, serum phosphorus was controlled solely with the use of calcium-containing phosphorus binders, and dialysate calcium concentration was set at 2.5 $\mathrm{mEq} / \mathrm{l}$ according to the protocol [10]. The increased use of non-calcium-containing phosphorus binders, cinacalcet and lower calcium bath may explain these apparently conflicting phenomena.

It should be noted that in the study of $2 \mathrm{MD}$ by Pandy et al. [7], cinacalcet was discontinued during the screening phase. Although dose adjustment of phosphorus binders was allowed during the study, it was not described in greater details. The reason for the replacement of paricalcitol with doxercalciferol in recent years in the USA is not quite clear but it may be related to the fiscal preferences of the dialysis industry, given the approximate 2 -fold higher cost of paricalcitol compared to doxercalciferol. Evaluating the cost-effectiveness of $2 \mathrm{MD}$ may be an important area of interest for future studies if $2 \mathrm{MD}$ is to gain acceptance among patients and providers.

In conclusion, Pandy et al. [7] showed promising results for $2 \mathrm{MD}$, a new active vitamin $\mathrm{D}$ analog, for the management of SHPT. Well-designed and better powered future studies with active control groups are necessary to evaluate relative long-term efficacy of $2 \mathrm{MD}$ on SHPT and calcium and phosphorus status in patients with CKD. Cost-effectiveness of the EMD administration needs to be examined as well.

\section{Disclosure Statement}

Dr. K. Kalantar-Zadeh has received honoraria from Abbott, Abbvie, Alexion, Amgen, Astra-Zeneca, Aveo, Chugai, DaVita, Fresenius, Genentech, Haymarket Media, Hospira, Kabi, Keryx, Novartis, Pfizer, Relypsa, Resverlogix, Sandoz, Sanofi, Shire, Vifor, UpToDate, ZS Pharma. The other authors have not declared any conflicts of interest. No other disclosures were reported.

References

Am J Nephrol 2016;43:221-224

1 Kalantar-Zadeh K, Shah A, Duong U, Hechter RC, Dukkipati R, Kovesdy CP: Kidney bone disease and mortality in CKD: revisiting the role of vitamin $\mathrm{D}$, calcimimetics, alkaline phosphatase, and minerals. Kidney Int Suppl 2010;117:S10-S21.

2 Kovesdy CP, Kalantar-Zadeh K: Vitamin D receptor activation and survival in chronic kidney disease. Kidney Int 2008;73:13551363.

3 Kalantar-Zadeh K, Kovesdy CP: Clinical outcomes with active versus nutritional vitamin D compounds in chronic kidney disease. Clin J Am Soc Nephrol 2009;4:1529-1539. 
4 Kalantar-Zadeh K, Miller JE, Kovesdy CP, et al: Impact of race on hyperparathyroidism, mineral disarrays, administered vitamin D mimetic, and survival in hemodialysis patients. J Bone Miner Res 2010;25:27242734.

5 Kalantar-Zadeh K, Kovesdy CP: Is it worth correcting hyperparathyroidism if hyperphosphatemia and hypocalcemia worsen? A cinacalcet story. Am J Kidney Dis 2009;53: 183-188.

6 Darabian S, Rattanasompattikul M, Hatamizadeh $\mathrm{P}$, et al: Cardiorenal syndrome and vitamin $\mathrm{D}$ receptor activation in chronic kidney disease. Kidney Res Clin Pract 2012;31:12-25.

7 Pandy R, Zella J, Clagett-Dame M, Plum L, Deluca H, Coyne D: Use of 2MD, a novel oral calcitriol analog, in hemodialysis patients with secondary hyperparahyroidism. Am J Nephrol 2016, in press.

8 DeLuca HF, Bedale W, Binkley N, et al: The vitamin $\mathrm{D}$ analogue $2 \mathrm{MD}$ increases bone turnover but not BMD in postmenopausal women with osteopenia: results of a 1-year phase 2 double-blind, placebo-controlled, randomized clinical trial. J Bone Miner Res 2011;26:538-545.

9 Slatopolsky E, Cozzolino M, Finch JL: Differential effects of 19-nor-1,25-(OH)(2)D(2) and 1alpha-hydroxyvitamin $\mathrm{D}(2)$ on calcium and phosphorus in normal and uremic rats. Kidney Int 2002;62:1277-1284.

10 Sprague SM, Llach F, Amdahl M, Taccetta C, Batlle D: Paricalcitol versus calcitriol in the treatment of secondary hyperparathyroidism. Kidney Int 2003;63:1483-1490.

11 Park J, Rhee CM, Lau WL, Kalantar-Zadeh K: Clinical uses of 1-alpha-hydroxy-ergocalciferol. Curr Vasc Pharmacol 2014;12:306-312.

12 Kovesdy CP, Lu JL, Malakauskas SM, Andress DL, Kalantar-Zadeh K, Ahmadzadeh S: Paricalcitol versus ergocalciferol for secondary hyperparathyroidism in CKD stages 3 and 4: a randomized controlled trial. Am J Kidney Dis 2012;59:58-66.

13 Kumar J, Tran N-T, Schomberg J, Streja E, Kalantar-Zadeh K, Pahl M: Successful conversion from parenteral paricalcitol to pulse oral calcitriol for the management of secondary hyperparathyroidism in hemodialysis patients. J Ren Nutr 2016, in press. 